\title{
Age group influence for effectiveness study of color symbol scheme on choropleth map of population density in special region of Yogyakarta
}

\section{Zulfa Nur'aini 'Afifah, . Sudaryatno}

Zulfa Nur'aini 'Afifah, . Sudaryatno, "Age group influence for effectiveness study of color symbol scheme on choropleth map of population density in special region of Yogyakarta," Proc. SPIE 11311, Sixth Geoinformation Science Symposium, 1131107 (21 November 2019); doi: 10.1117/12.2546072

EDIE Event: Sixth Geoinformation Science Symposium, 2019, Yogyakarta, Indonesia 


\title{
Age group influence for effectiveness' study of color symbol scheme on choropleth map of population density in Special Region of Yogyakarta
}

\author{
Zulfa Nur'aini 'Afifah', Sudaryatno ${ }^{\mathrm{b}}$ \\ Dept. of Geographic Information Science, Universitas Gadjah Mada, Bulaksumur, Yogyakarta \\ azulfa.nuraini@mail.ugm.ac.id \\ bsudaryatno@ugm.ac.id \\ Corresponding author's email: \\ zulfa.nuraini@mail.ugm.ac.id
}

\begin{abstract}
Map can show information needed by map users from various scientific fields. Effective maps can help users to understand about the information inside. One of the factors that influence the effectiveness of map reading is color symbol scheme used in symbolization. Effectiveness' study of color symbol scheme applied on choropleth mapping. Choropleth map visualized population density data in Special Region of Yogyakarta because the Special Region of Yogyakarta is one of the provinces in Indonesia which has a fairly high population density in the area of $3,185.80 \mathrm{~km}^{2}$. In 2016, the population density of the Special Province of Yogyakarta ranked $4^{\text {th }}$ in the Indonesian Statistics 2017 by the Central Bureau of Statistics, which amounted to 1,188 population per $\mathrm{km}^{2}$. All scientific field that used choropleth map of population density consist of 2 age groups, those are 20-25 years old and $>25$ years old respondents. Visual abilities in different age groups of map users can be accommodated with this research. The effectiveness of color symbol schemes adapts the capabilities of each user. This study is expected to be able to study the effect of age group differences on maps with the best color symbol scheme. The purpose of this study was to observe age group influence for the most effective color symbol scheme for mapping population density in the Special Region of Yogyakarta. The result of this study shows the difference between age group based on the important aspects of conventional-eye tracking. The important aspects to consider are average answering duration, the accuracy of the answer and easiness level of symbolization readings. The first group (20-25 years) shows map 3 (diverging color scheme) as a map with the most effective color symbol scheme. While group 2 (> 25 years) shows map 1 (ArcGIS 10.3 color scheme) as a map with the most effective color symbol scheme. This research is expected to be able to show the influence of age in determining the best color symbol scheme on population density maps so that its effectiveness can be adjusted specifically to map users.
\end{abstract}

Keywords: color symbol scheme, choropleth map, conventional eye-tracking, population density mapping, Yogyakarta, age group

\section{INTRODUCTION}

Thematic maps have many types, one of which is the choropleth map. Choropleth map is a map that presents information on area dimensions using the intensity of gray area symbols to represent the intensity of a geographic phenomenon spatially (Kraak and Ormeling, 2007) ${ }^{[1]}$. The ultimate goal of the representation of thematic maps is to give a credible impression of the pattern of spatial data presented in them (Al-ghamdi, 2014) ${ }^{[2]}$. Choropleth maps can present data and information with various themes in various scientific fields. This is also needed for novice users of the map who want to get knowledge or insights from the information that is represented or written on the choropleth map. Good understanding can be a guide to making good decisions.

In addition, considering the choropleth map is a type of mapping that poses visual variables in the form of values that are manifested in gradual color schemes that have quantitative levels of visual perception, this study will examine the effectiveness of color symbol schemes. Choropleth maps are maps that represent quantitative data with interval / ratio data, so that a color scheme is needed that can lead to quantitative visual perception. Visual variables that can be used in choropleth maps are texture / density, value / gray and color. Based on the theory of color isolation by Bertin, it was suggested that the visual texture / density and value / gray variables used to symbolize the area dimensions only present up to 5 levels of data classification. While the visual color variable can accommodate up to 8 levels according to the population density data that is to be represented in the demographic mapping for Special Region of Yogyakarta with 78 sub-districts in 4 districts and 1 city. 
Some research in thematic maps shows that in cartography, color can be used to represent important information related to geographical phenomena. Therefore, the level of a user's ability to match or distinguish colors is very important to identify spatial information in a map visually, such as spatial patterns or anomalies. The visual identification of patterns and anomalies depends on whether the map user can see the difference between one color and the other. The level of map users' ability to match colors or distinguish colors depends on design choices (chromatic differences and spatial gaps between colors), as well as differences in individual physiological abilities in perceptual abilities (Brychtova and Coltekin, 2017) ${ }^{[3]}$.

Quantitative visual variables are quite widely used in mapping quantitative statistical data, as stated by White, et al. (2017) ${ }^{[4]}$. From 2004 to 2013 approximately 440 journals which included statistical maps in them using color as visual variables to represent the data inside. Color symbol schemes is considered to be quite representative and easy to use, but so far there has been no response from users of the map about the ease of symbol reading on the map, especially if the classification of data includes a lot of classes. The development of cartography from the beginning, which only represents data in accordance with the map maker, has shifted to adjusting the needs and requests of map users so that the effectiveness of the color symbol scheme used in choropleth map is needed to accomodate map user's ability.

This study is expected to study the effect of age group differences on maps with the most effective color symbol scheme. All scientific field that used choropleth map of population density consist of 2 age groups, those are 20-25 years and $<25$ years. Visual abilities in different age groups of map users can be accommodated by this research and find effective color symbol schemes for each age group more specifically. The purpose of this study was also to observe age group influence for the most effective color symbol scheme for mapping population density in the Special Region of Yogyakarta. The result of this study shows the difference between age group based on the important aspects of conventional-eye tracking. The important aspects to consider are average answering duration, the accuracy of the answer and easiness level of symbolization readings. The method discussed in this study is also expected to be applicable to other data. 


\section{STUDY AREA}

The selection of study areas in the Special Region of Yogyakarta was due to the fact that in 2016, the population density of the Special Region of Yogyakarta was ranked $4^{\text {th }}$ in the Indonesian Statistics of 2017 by the Central Bureau of Statistics ${ }^{[5]}, 1,188$ population per $\mathrm{km}^{2}$. Administratively the Special Region of Yogyakarta consists of 4 districts. Those are divided into 78 sub-districts, and 438 villages. Based on geographically position, the Special Province of Yogyakarta is located in the south-central part of Java Island and astronomically located at $8^{\circ} 30^{\prime}-7^{\circ} 20^{\prime}$ South Latitude, and $109^{\circ} 40$ '- $111^{\circ} 0$ ' East Longitude according to figure 1. Administratively, the Special Province of Yogyakarta borders on several regions, namely Indian Ocean (South), Boyolali Regency, Central Java (North), Wonogiri Regency, Central Java (East) and Purworejo Regency, Central Java (West).

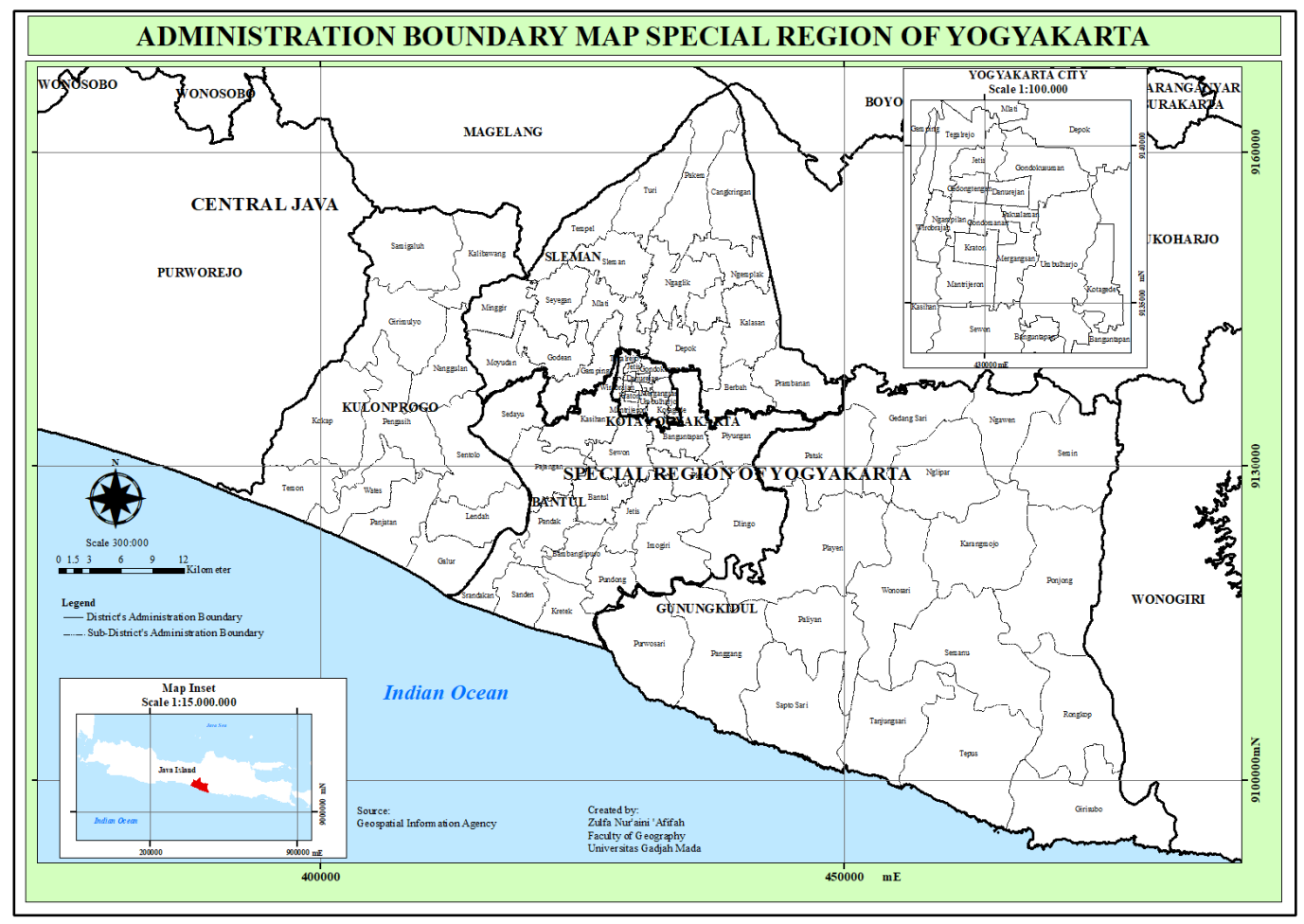

Figure 1 Map of Research's Area

\section{METHODOLOGY}

\subsection{Tools and Materials}

\section{Research Tools}
a. Laptop to process the data which is equipped with: ArcGIS 10.3, SPSS/Microsoft Excel, Corel Draw, and Google Chrome
b. Stationary
Research Materials dan Datasets
a. Data of Total Population in Special Region of Yogyakarta
b. Data of Shapefile in Special Region of Yogyakarta
c. Questionnaire and Printed Map/Album of Conventional Choropleth Map

\subsection{Step of Research}

\section{Data Classification}

a. Number of Data Classfication 
The stages of making data classifications:

1. Determining the data type

2. Limiting the number of classes using Sturgess, Number of classes $=1+3.3 \log$ (amount of data)

3. Determining the lowest class boundaries and following other boundaries.

b. Classification Method:

The arithmetic classification method uses intervals obtained from the highest value and the lowest value of the available data then divided by the number of previously calculated classes. This interval is used as a variable multiplied by a certain coefficient of each class addition in each class as a result of classification.

\section{Symbolization}

Color symbol scheme used in this study to coloring is generated by http://colorbrewer2.org according to Brewer (2013)

${ }^{[6]}$ which consists of sequential, diverging and qualitative. However, in this study the color symbol scheme to be analyzed is Sequential Color Symbol Schemes, both single and multi-hue, Diverging Color Symbol Scheme, Manual Color Scheme created by Corel Draw and original color symbol schemes available in ArcGIS 10.3 software. Total class for data based on the calculation above is 7 classes of population density. Below in table 1 is the RGB composition color symbol scheme used in this study:

Table 1. Color symbol scheme

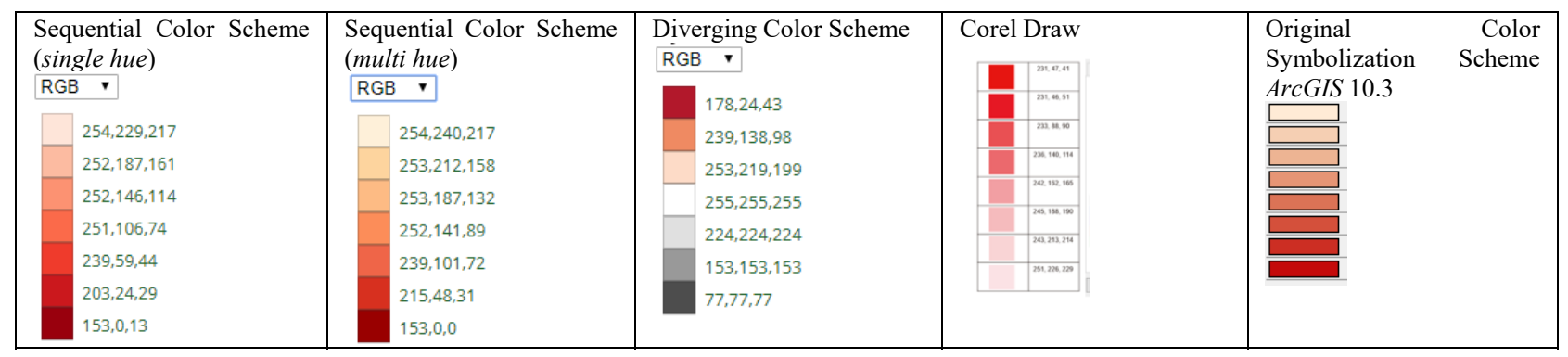

\section{Most Effective Color Symbol Scheme Test}

Based on to the research done by Brychtova and Coltekin (2015) ${ }^{[7]}$, Eye Tracking method is trying to find out the quickness of map user in differentiating or identifying population density class' color symbol scheme on choropleth map. Important aspects used in this study are average duration of answering, the accuracy of the answer and the easiness level of symbolyzation readings.

This study is applied the method above conventionally. Conventional eye tracking is done by using printed choropleth map and questionnaires. Duration calculated by stopwatch in unit of seconds. This method is used in the test of the most effective color symbol scheme with these stages as follows:

1) Creating A Map User Sample Scheme

Samples involved in conventional eye tracking are all people who are thought to be users of the choropleth map. The sample of the map users consisted of 2 age groups. The first group is students aged 20-25 years who are estimated to use the choropleth map for learning or research. Whereas the second group is staff from the government with the age above 25 years. The sampling method is purposive sampling because all samples are expected to be compatible with the sample scheme made by map maker with the aim of this study.

2) Creating Questionnaire

Questionnaire which is created to test the most effective color symbol scheme consists of choropleth map of Population Density in Special Region of Yogyakarta using different color symbol scheme which is printed in A3 size and questions about the map associated with important aspects of conventional eye tracking. The questions' answer is collected on online form.

3) Questionnaire Distribution

Distribution of questionnaire is held in Special Region of Yogyakarta. Map user samples who filled the questionnaire are expected to be able to represent the ability of the user in reading the map with color symbol scheme used in choropleth map symbolization, both expert map users and novice map users.

4) Tabulating the results through the online form.

The results represented on graphs and tables. 


\section{RESULTS AND DISCUSSIONS}

Choropleth map with different color symbol scheme is marked without differentiating the title of the map based on table 2 below. The first map uses color symbol scheme which is available in the software ArcGIS 10.3 called ArcMap Color Ramp. The second map uses Manual Color Schemes which is created using the software Corel Draw. The third map uses Diverging Color Schemes. The fourth map uses Sequential Color Schemes in Multi Hue and the last map uses Sequential Color Schemes in Single Hue.

Table 2. Choropleth Maps using different color symbol scheme

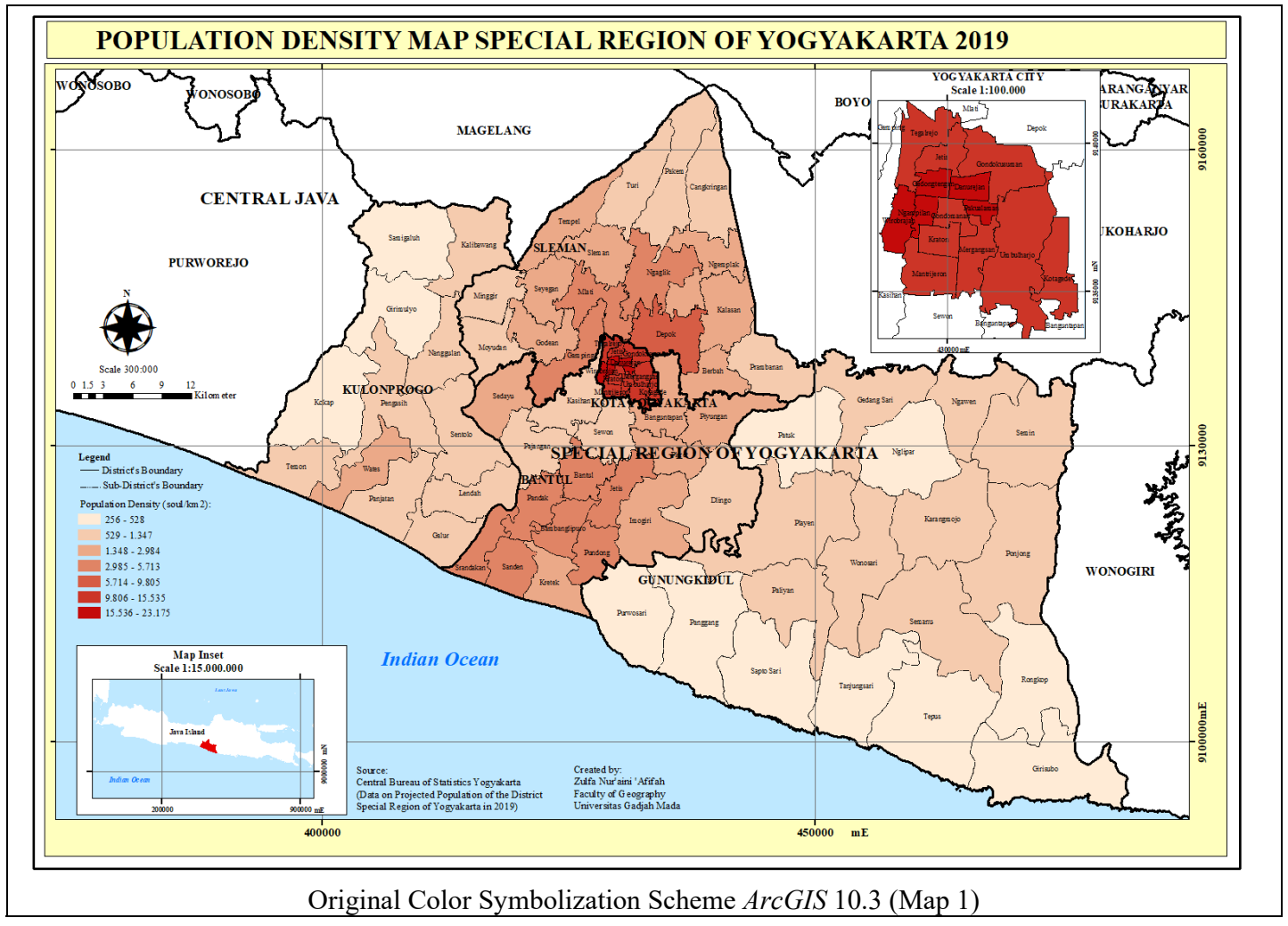




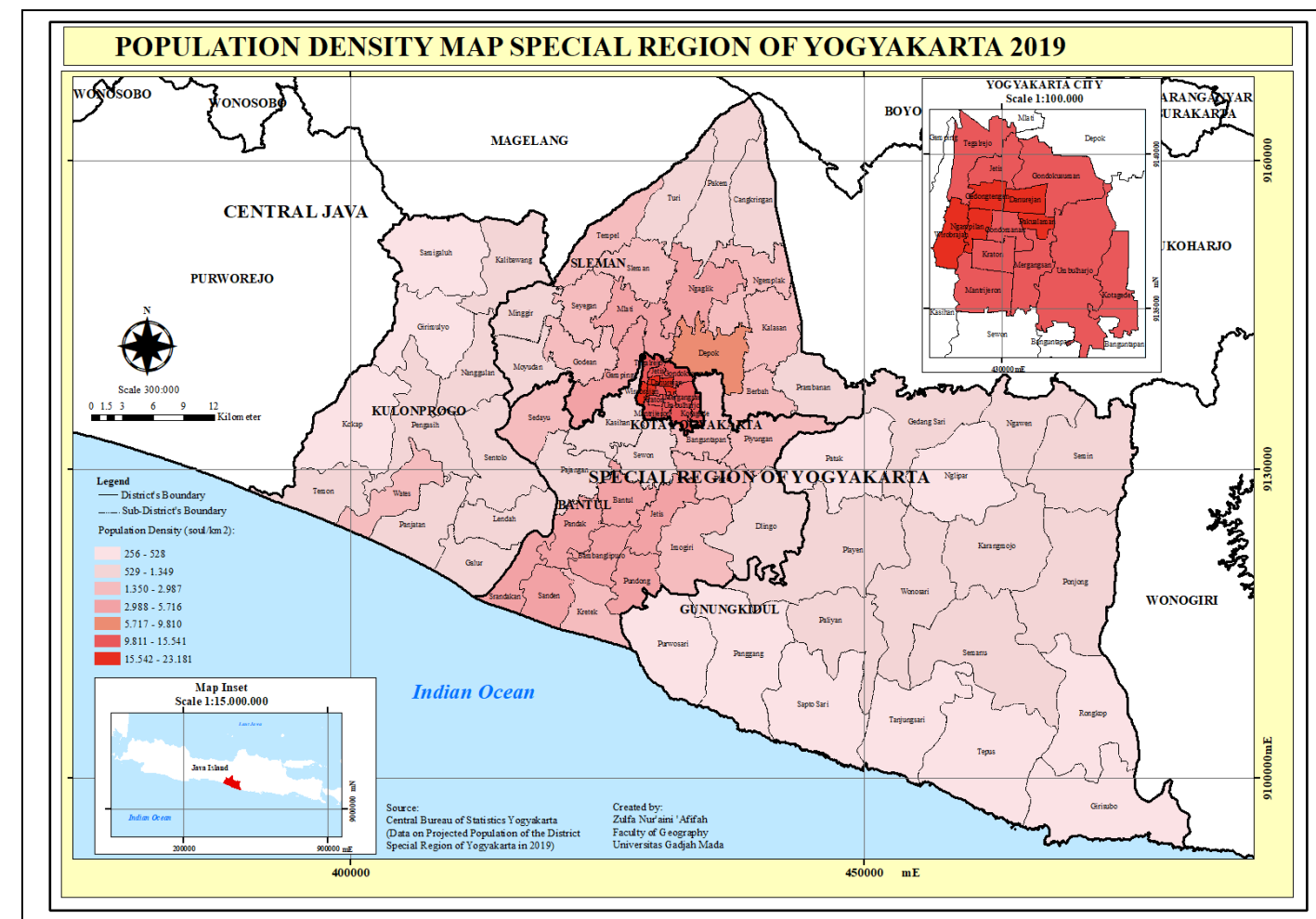

Color Scheme created by Corel Draw (Map 2)

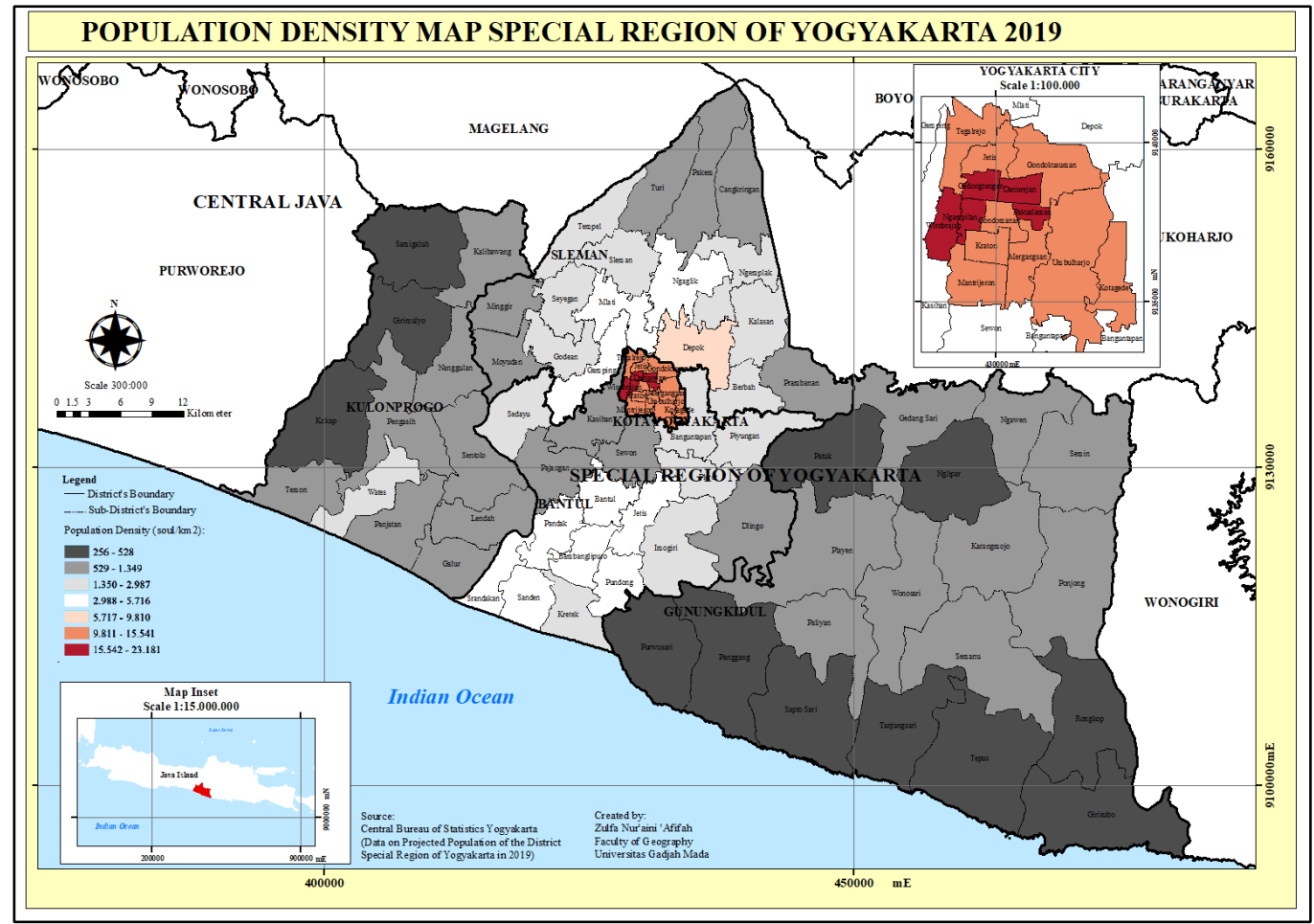

Diverging Color Symbol Scheme (Map 3) 


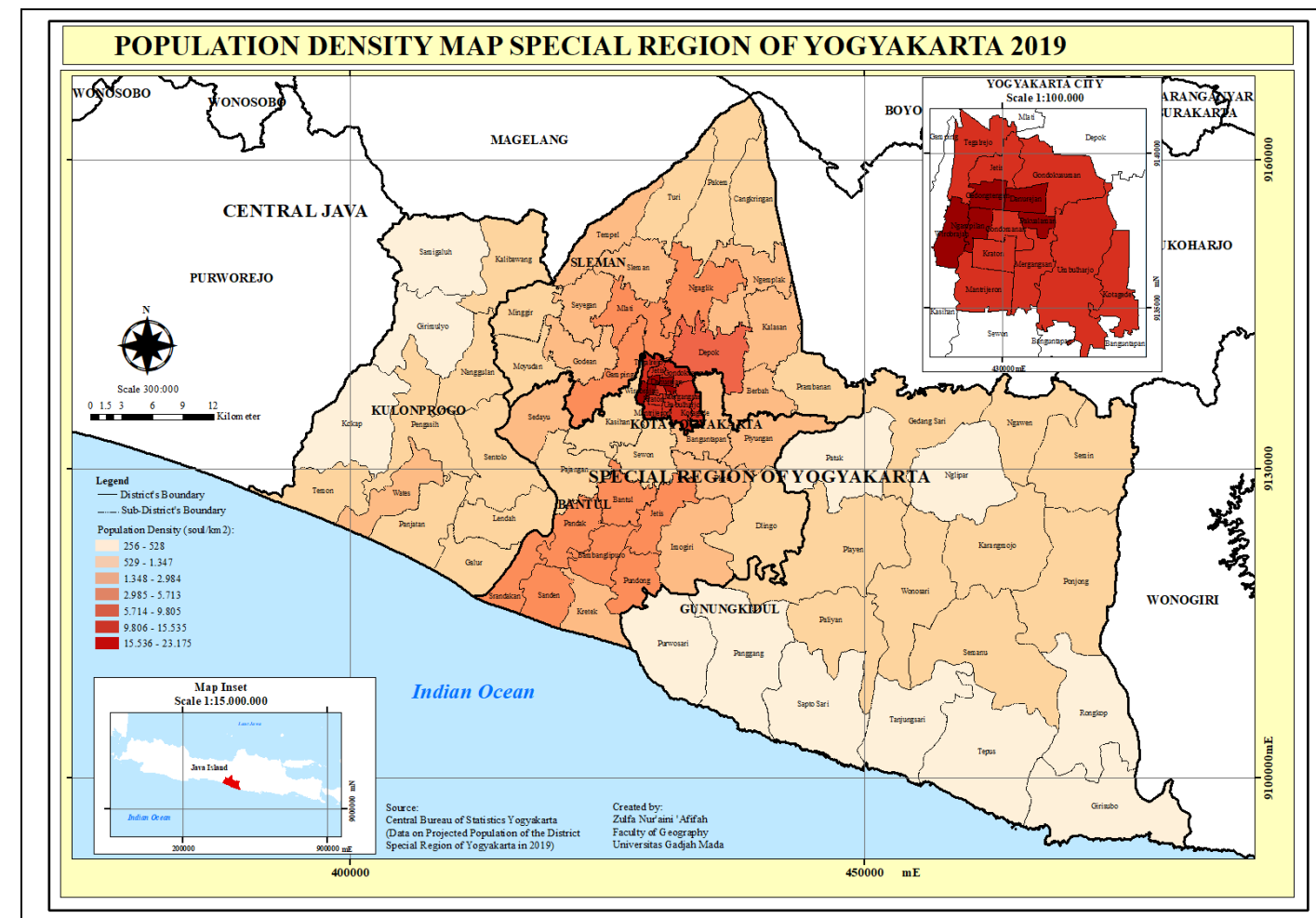

Sequential Color Scheme (multi hue) (Map 4)

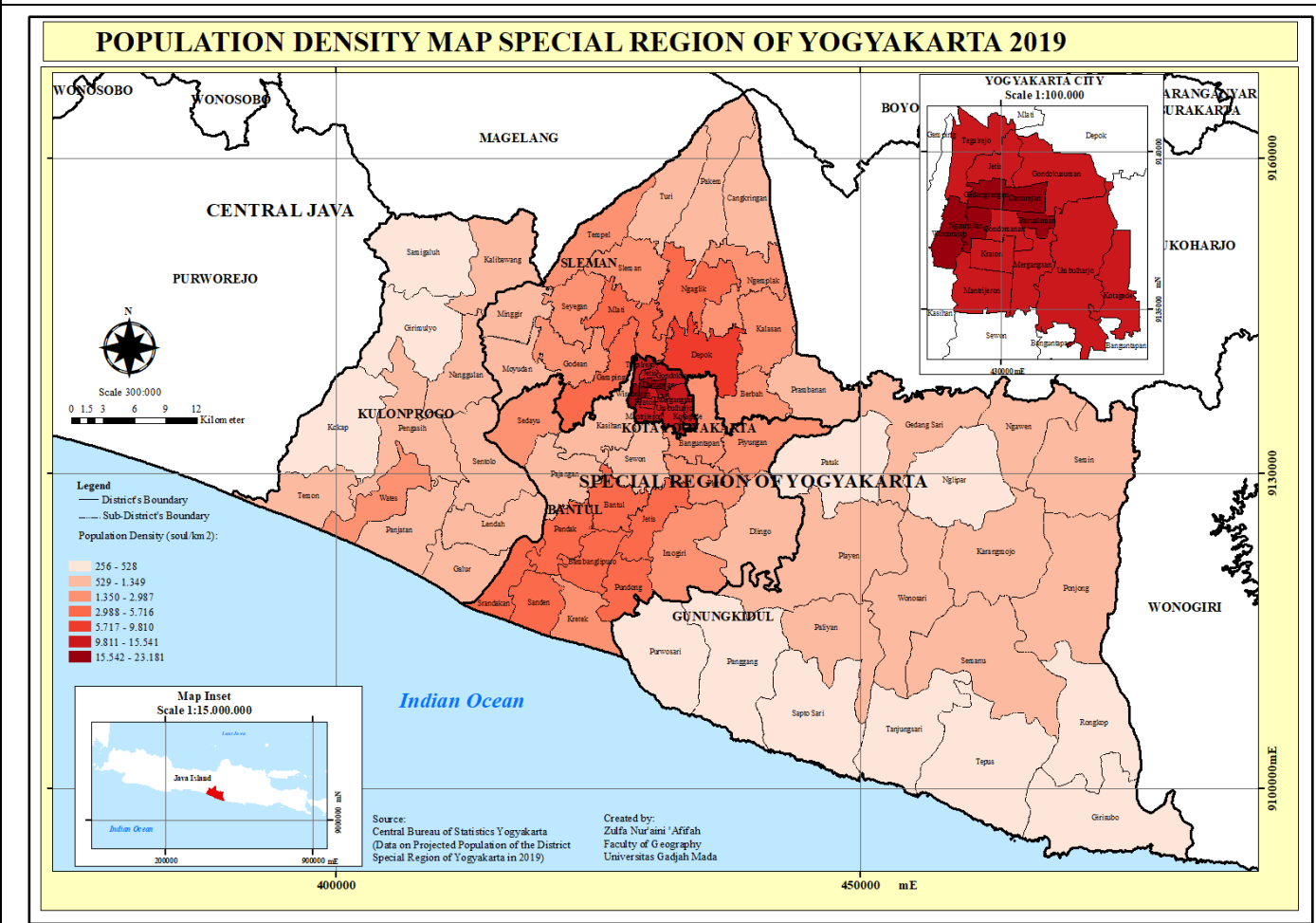

Sequential Color Scheme (single hue) (Map 5) 
The effectiveness of color symbol schemes adapts the capabilities of each user. This study is expected to be able to study the effect of age group differences on maps with the best color symbol scheme. All scientific field that used choropleth map of population density consist of 2 age groups, those are 20-25 years old and $>25$ years old respondents. Map user samples which are 45 students represent the user age from 20-25 years old. Population density map can be used by students who are carrying out some researches or materials for studying. Samples from 45 institution staffs $(>25$ years old) can represent the heterogenous field of study which use map as a stake holder and decision maker.

There is 1 respondent who has color impairment, he is a familiar map institution staff. The respondent claimed that the conventional eye-tracking method had no effect in reading the population density maps compared in this study. The results obtained for him were also not much different from other respondents before. However, the results might be different if the respondents who have color impairment are unfamiliar map (novice) respondents.

The result of this study shows the difference between age group based on the important aspects of conventional-eye tracking. The important aspects to consider are average answering duration, the accuracy of the answer and easiness level of symbolization readings. The following is a review of the most effective color symbol schemes of each of the important aspects in conventional eye-tracking:

\subsection{Average Answering Duration}

Overall, the duration taken by the students and institution staffs shows the easiness in reading symbolization of subdistricts as an object of interest. According to figure 2 below the quickest average answering duration was on map 1 which was 7.77 seconds for student respondents and 5.91 seconds for institution staff respondents. It shows that affects the duration taken to answer is the selection of sub-district which can be seen from symbol distribution as a comparison and choice of color symbol scheme's RGB composition. Color symbol of Patuk Sub-district as object of interest on map 1 is easier compared to other sub-districts around. Aside from that, the selection of color symbol scheme is quite effective. Map user aging above 25 years old tends to be quicker in reading the map compared to those aging 20-25 years old. This can be caused by the institution staffs having experiences in observing the map, so that they are able to answer quicker.

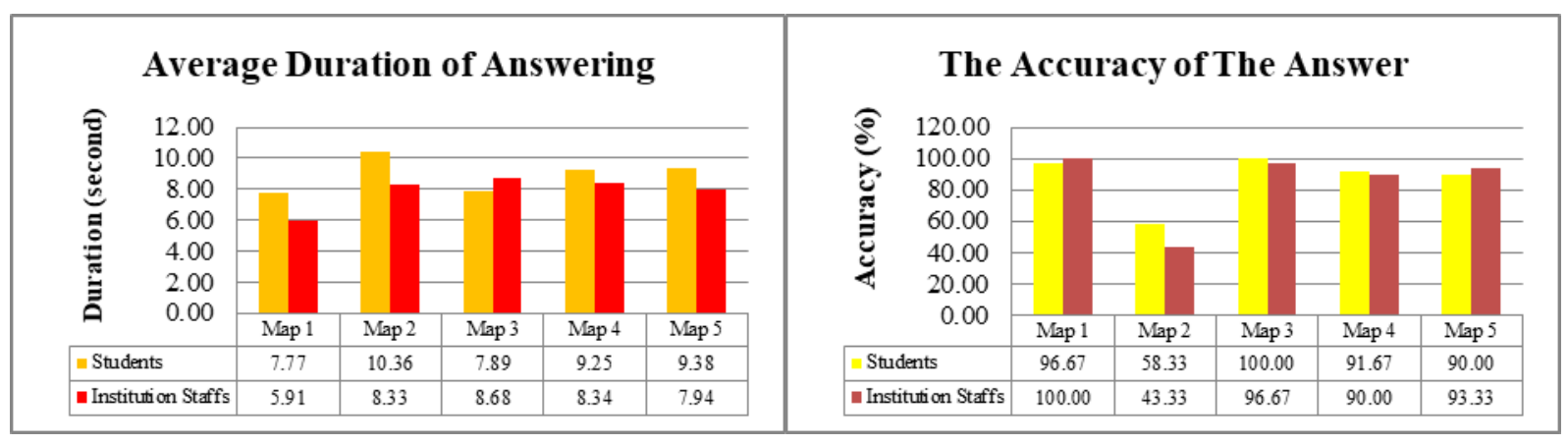

Figure 2 Average Duration of Answering

Figure 3 The Accuracy of The Answer

\subsection{The Accuracy of The Answer}

Based on the figure 3 above, all of the students map user samples are able to correctly answer the questions on map 3 meanwhile all of institution staffs map user samples are able to correctly answer the questions on map 1 . The results obtained show the difference between 2 age group based on the accuracy of the answer. Answers accuracy shows the ability in reading the maps of sub-districts as an object of interest on each map user samples. The answers accuracy also shows that the selection of sub-district as an object of interest on map 3 are the most ideal ones and easier to interpret. Furthermore, the most important is the answers accuracy with correct percentage of $100 \%$ shows that the selection of color symbol scheme is the most effective among the other maps for map user aging 20-25 years old and 25 years old. 


\subsection{Easiness Level of Symbolization Reading}

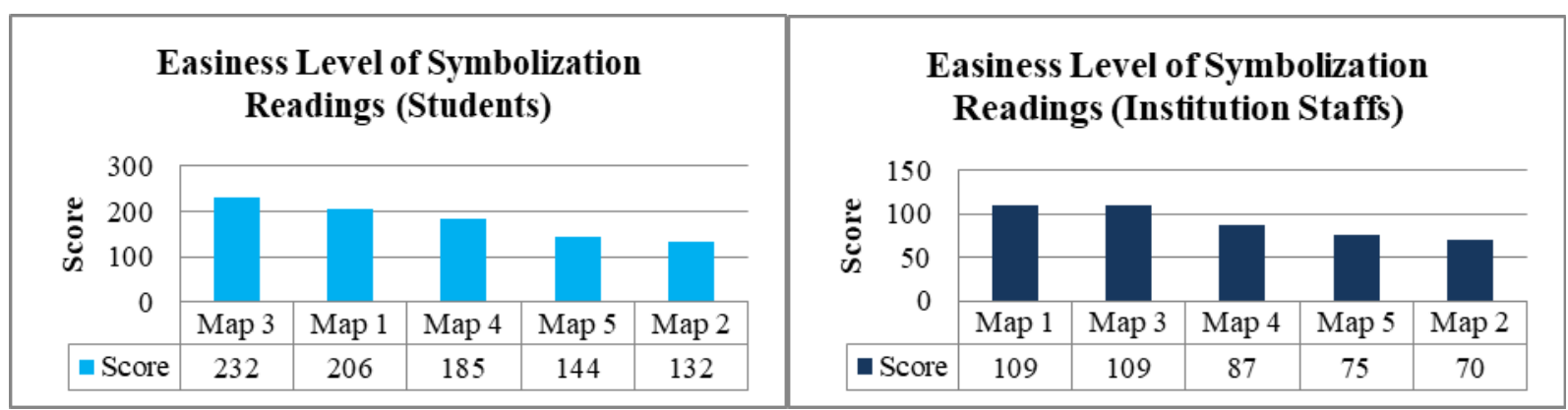

Figure 4 Easiness Level of Symbolization Readings Score Graphic for Students

Figure 5 Easiness Level of Symbolization Readings Score Graphic for Instituion Staffs

Easiness level of symbolization reading of all five maps are very easy, easy, average, difficult and very difficult. Each level has a score. Highest score is 5 for map that is very easy to read and lowest score is 1 for map that is very difficult to read. Total scores of each map is obtained from the total scores of level of easiness in reading symbolization. Based on figure 4 above, the highest score is 232 for map 3. This shows the selection of the most effective color symbol scheme among the other maps for map users aging $20-25$ years old.

Meanwhile, based on figure 5, the highest score is 109 for map 3 and map 1. This shows the selection of color schemes and original color symbol scheme by ArcGIS are the most effective among the other maps for map users aging above 25 years old. Map 1 is symbolized using original color symbol scheme provided by ArcGIS whereas used red as primary color. Map user samples claim that map 1 has a good contrast between classification classes. Moreover, map users feel that the selection of sub-district as an object of interest is easier to compare with other sub-districts around spatially. The result obtained is different from overall result on students as map users aging $20-25$ years old explained before.

This shows that age factor can affect the effectiveness of color symbol scheme especially for easiness level of symbolization readings aspect. Institution staffs complained that toponymal writing on the black gradation color which is used on map 3 made it less visible. That can be concerned with lower ability of sight due to age factor. Additionally, according to institution staffs, they frequently look at maps with gradation color using only 1 primary color.

Table 3. Summary of Important Aspect of Conventional Eye-tracking

\begin{tabular}{|c|c|c|}
\hline Important Aspect & Students (20 - 25 years old) & Institution Staff (>25 years old) \\
\hline Average Answering Duration & 7.77 seconds (Map 1) & 5.91 seconds (Map 1) \\
\hline The Accuracy of The Answer & $100 \%$ true on Map 3 & $100 \%$ true on Map 1 \\
\hline Easiness Level of Symbolization Reading & Highest score on Map 3 & Highest score on Map 1 and map 3 \\
\hline
\end{tabular}

Based on the summary in table 3 above, it can be concluded that age can influence conventional eye-tracking results. Difference in age groups of respondents who were incorporated in this study showed the results of the effectiveness of different color symbol schemes. The most effective color symbol scheme for the 20-25 year age group with student respondents is map 3 with the diverging color symbol scheme from colorbrewer.org. While the most effective color symbol scheme for the age group above 25 years with institution staff respondents is map 1 with the original color symbol scheme from ArcGIS. There are a number of things that can make the age group influence these results. The first factor suspected of being able to make this difference is the experience on map reading, especially the experience of distinguishing color symbols. The second factor is the physicality of each respondent with a different age. Physical factors meant here are the conditions of vision ability for each respondent. The third factor is the psychological tendency towards colors presented on the map. So that from the results of the research that has been done, it is expected that the presentation of choropleth maps can also adjust the age of map users more specifically. 


\section{CONCLUSIONS}

Based on the research that has been done, the conclusion is obtained to answer the research objectives as follows:

There is an influence of age groups on the study of the effectiveness of color symbol schemes for choropleth maps of population density in Special Regions of Yogyakarta so that the tendency of the most effective color symbol schemes for the two age groups of respondents involved in this study is different.

\section{REFERENCES}

[1] Kraak, Menno-Jan and Ormelling, Ferjan, [Kartografi dan Visualisasi Data Geospasial. Translator: Sukendra Martha, dkk] Gadjah Mada University Press, Yogyakarta (2007)

[2] Al-Ghamdi, Ali M.,"Optimising the Selection of a Number of Choropleth Map Classes", Lecture Notes in Geoinformation and Cartography: Thematic Cartography for the Society , 61-78 (2014)

[3] Brychtova, Alzbeta and Coltekin, Arzu, "The effect of spatial distance on the discriminability of colors in maps", International Journal of Cartography, 44(3), (2017)

[4] White, Travis M.,dkk, "Trends and Issues in the Use of Quantitative Color Schemes in Refereed Journals", Annals of the American Association of Geographers, 107(4), (2017)

[5] Central Jakarta Statistic Center, [Indonesian Statistics 2017], Central Jakarta, Central Statistics Agency, (2017)

[6] Brewer, Cynthia A, et al., "ColorBrewer in Print: A Catalog of Color Schemes for Maps", Cartography and Geographic Information Science Journal, 30(1), (2013)

[7] Brychtova, Alzbeta and Coltekin, Arzu, "Discriminating classes of sequential and qualitative colour schemes", International Journal of Cartography, 1(1), (2015) 